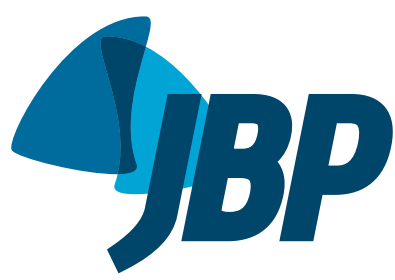

1. Unidade de Terapia Intensiva Adulto, Hospital Moinhos de Vento, Porto Alegre (RS) Brasil.

2. Departamento de Pneumologia, Hospital Moinhos de Vento, Porto Alegre (RS) Brasil.

3. Serviço de Pneumologia, Hospital de Clínicas de Porto Alegre, Porto Alegre (RS) Brasil.

4. Programa de Pós-Graduação em Ciências Pneumológicas, Universidade Federal do Rio Grande do Sul, Porto Alegre (RS) Brasil.

Submitted: 24 February 2015

Accepted: 29 June 2015.

Study carried out at the Unidade de Terapia Intensiva Adulto of the Hospital

Moinhos de Vento; and under the auspices of the Programa de Pós-

Graduação em Ciências Pneumológicas,

Universidade Federal do Rio Grande do

Sul, Porto Alegre (RS) Brasil.

\title{
Inhalation therapy in mechanical ventilation
}

\author{
Juçara Gasparetto Maccari', Cassiano Teixeira', Marcelo Basso Gazzana², \\ Augusto Savi', Felippe Leopoldo Dexheimer-Neto', Marli Maria Knorst'
}

\begin{abstract}
Patients with obstructive lung disease often require ventilatory support via invasive or noninvasive mechanical ventilation, depending on the severity of the exacerbation. The use of inhaled bronchodilators can significantly reduce airway resistance, contributing to the improvement of respiratory mechanics and patient-ventilator synchrony. Although various studies have been published on this topic, little is known about the effectiveness of the bronchodilators routinely prescribed for patients on mechanical ventilation or about the deposition of those drugs throughout the lungs. The inhaled bronchodilators most commonly used in ICUs are beta adrenergic agonists and anticholinergics. Various factors might influence the effect of bronchodilators, including ventilation mode, position of the spacer in the circuit, tube size, formulation, drug dose, severity of the disease, and patient-ventilator synchrony. Knowledge of the pharmacological properties of bronchodilators and the appropriate techniques for their administration is fundamental to optimizing the treatment of these patients.
\end{abstract}

Keywords: Bronchial hyperreactivity; Drug delivery systems; Respiration, artificial.

\section{INTRODUCTION}

Patients with obstructive lung disease, such as COPD and bronchial asthma, often require ventilatory support via invasive mechanical ventilation (MV) or noninvasive MV (NIMV), depending on the severity of the exacerbation. Many such patients have increased airway resistance and, consequently, airway obstruction, which results in increased positive end-expiratory pressure (PEEP) and, consequently, auto-PEEP (also known as dynamic hyperinflation). Auto-PEEP results in increased respiratory effort, contributing to muscle fatigue in such patients. ${ }^{(1)}$ Therefore, the use of positive pressure MV can improve respiratory function, improving the outcomes of decompensated patients. ${ }^{(2)}$ The use of inhaled bronchodilators can significantly reduce airway resistance, contributing to the improvement of respiratory mechanics and patient-ventilator synchrony.

The major advantages of using inhalation therapy in such patients are selective treatment of the lungs and high drug concentrations in the airways. In addition, inhaled drugs have a more rapid onset of action and fewer systemic adverse effects than do drugs administered by other routes. However, correct inhaler technique and regular medication use are needed in order to improve drug efficacy, given that inhaled drugs have shorter half-lives.

In a recently published study, physician practices regarding the prescription of inhaled drugs were analyzed in 70 countries. ${ }^{(2)}$ Of the 854 intensivists whose responses were analyzed, $99 \%$ reported prescribing aerosol therapy to patients on MV, including those on NIMV, and $43 \%$ exclusively used nebulizers. During nebulization, ventilator settings were never changed by $77 \%$ of the respondents; in addition, $87 \%$ stated that ultrasonic nebulizers were superior to jet nebulizers. The aforementioned study provides evidence of the heterogeneity in prescribing inhaled drugs, showing that current scientific knowledge is poorly applied.

Although various studies have been published on this topic, little is known about the efficacy of the bronchodilators routinely prescribed for patients on MV or about the deposition of those drugs throughout the lungs. The use of inhaled drugs in patients requiring NIMV poses an even greater challenge.

\section{INHALATION THERAPY DURING MV}

The use of inhaled drugs has the advantage of allowing selective treatment of the lungs by delivering high drug concentrations to the airways, having a rapid onset of action and few systemic adverse effects. It is believed that the beneficial effects of inhaled drugs are smaller in patients on MV than in those breathing spontaneously. In an early study, only $2.9 \%$ of the administered dose reached the distal airway (vs. $11.9 \%$ when the dose was administered without an artificial airway) $)^{(3)}$; this might be due to a substantial drug loss caused by the turbulent flow produced by the respiratory prosthesis. However, precautions observed at the time of drug

Correspondence to:

Cassiano Teixeira. Rua Ramiro Barcelos, 910, CEP 90035-001, Porto Alegre (RS) Brasil.

Tel.: 5551 3314-3387.

E-mail: cassiano.rush@gmail.com

Financial support: None. 
administration can improve lung drug deposition, ${ }^{(4)}$ as shown in Chart 1.

With regard to aerosol delivery devices, it was initially believed that lung drug deposition was better with the use of metered dose inhalers (MDIs) than with the use of conventional nebulizers. ${ }^{(5)}$ However, when the two types of devices are used correctly, the results are similar. ${ }^{(6,7)}$ In general, MDIs are more economical and pose a lower risk of nosocomial pneumonia. ${ }^{(4,7)}$ Clinical studies have shown that nebulizers and MDIs have similar effects on lung function, both types of devices resulting in equivalent changes in $\mathrm{FEV}_{1}{ }^{(6)}$

Bronchodilators, corticosteroids, antibiotics, prostaglandins, nitric oxide, anticoagulants, and heliox can be administered via inhalation. However, inhalation is most commonly used for bronchodilator administration, improving ventilatory parameters and patient-ventilator synchrony in cases of airway constriction. ${ }^{(8)}$ Bronchodilators relax airway smooth muscles, reversing airway obstruction and preventing bronchoconstriction. ${ }^{(6)}$ Ventilator-dependent patients, COPD patients, and asthma patients routinely receive treatment with inhaled bronchodilators.

\section{PHARMACOLOGICAL AGENTS}

The inhaled bronchodilators that are most commonly used in the ICU are beta adrenergic agonists and anticholinergics. ${ }^{(8)}$ Beta adrenergic agonists can also be administered intravenously, subcutaneously, or orally; however, inhalation is the preferred route of administration because of direct lung delivery, need for a lower dose, rapid onset of action, and reduced systemic absorption, thus reducing adverse effects. ${ }^{(6,8,9)}$ One study evaluated the emergency room treatment of patients with asthma and showed that there is no evidence to support the use of intravenous $\beta_{2}$ agonists, even in patients refractory to inhaled $\beta_{2}$ agonists. ${ }^{(10)}$ Chart 2 shows the inhaled bronchodilators that are most commonly used in the ICU, including doses and pharmacological characteristics such as onset of action, time to peak effect, and duration of action.

\section{CLINICAL USE OF BRONCHODILATORS}

In patients with COPD, long-acting $\beta_{2}$ agonists and inhaled corticosteroids are used in order to relieve symptoms, improve quality of life, improve lung function, and prevent decompensation. ${ }^{(8)}$ In patients with exacerbation of COPD or severe asthma, emergency bronchodilator treatment is required. The drug of choice is a short-acting $\beta_{2}$ agonist (e.g., albuterol), because short-acting $\beta_{2}$ agonists have a more rapid onset of action and a greater bronchodilator effect and because they can be repeated at short intervals during bronchospasm attacks. ${ }^{(6)}$ The need for high doses in critically ill patients has led to studies of continuous nebulization in selected patients. However, the results are conflicting, showing no evidence that this strategy is beneficial. ${ }^{(6,11)}$
In general, the severity of asthma or COPD exacerbation can be best evaluated by the severity of the attack and the bronchodilator response than by previous lung function.

\section{FACTORS THAT INFLUENCE INHALED DRUG DELIVERY DURING MV}

In patients on MV, bronchodilators can be delivered by jet nebulizers, ultrasonic nebulizers, or MDIs. In the case of jet nebulizers, compressed gas generates aerosol particles that are delivered with tidal volume. This necessarily increases the tidal volume delivered in each inspiratory cycle. Ultrasonic nebulizers are available for certain ventilators. They deliver medicine by using high-frequency vibrations to convert the liquid into an aerosol and do not increase patient tidal volume during inhalation.

To date, no clinical differences have been found between jet and ultrasonic nebulizers. ${ }^{(6)}$ The disadvantages of conventional nebulizers include the need for an external flow source independent of the ventilator, the need to install the equipment, and the need for thorough cleaning. Ultrasonic nebulizers can provide a higher nebulization rate in a shorter period of time; however, their availability is limited by high cost. ${ }^{(6)}$

Studies investigating clinical differences between nebulizers and MDIs have yielded inconsistent results. The efficacy of MDI-delivered drugs depends particularly on the position of the tube in the ventilator circuit. In the case of MDI-delivered bronchodilators, a spacer is essential and can increase aerosol deposition in the airways by four to six times. ${ }^{(12-14)} A$ variety of spacers are available. It is currently believed that an MDI with a spacer is as effective as a nebulizer, being more practical and quicker to administer and requiring no disconnection from the ventilator circuit after each dose.

Many other factors influence aerosol deposition in the lower airways, as shown in Chart 3. Such factors include drug-related properties (including physical and chemical properties), the characteristics of the aerosol generator, the position of the aerosol generator in the ventilator circuit, ventilator settings, ventilation modes, heating and humidification of the inhaled air, the characteristics of the endotracheal tube, the anatomy of the airways, and the presence of respiratory secretions. ${ }^{(15-17)}$

Even in ventilator-dependent patients, bronchodilators should preferentially be administered with the head of the bed elevated, given that the sitting position improves drug delivery. ${ }^{(16)}$ Heating and humidification of the inhaled air are required during ventilatory support in order to reduce the risk of ventilator-associated pneumonia. However, they increase particle impaction in the ventilator circuit, reducing aerosol deposition in the more distal airways by as much as $40 \%$. ${ }^{(12,13)}$

The aerosol generator should be placed at a distance of $20-30 \mathrm{~cm}$ from the endotracheal tube, between the tube and the Y-piece of the ventilator circuit, $(16,18,19)$ as shown in Figure 1. This is due to the fact that the 
Chart 1. Strategies to improve lung drug deposition during mechanical ventilation.

Ventilator-related strategies
Deliver a tidal volume $>500 \mathrm{~mL}^{\mathrm{a}}$
Maintain an inspiratory flow of $30-50 \mathrm{~L} / \mathrm{min}$
Avoid delays between actuation and inhalation
Circuit-related strategies
Remove the filter or deliver the drug at a location more proximal to the filter
Turn the humidifier off 10 min before aerosol delivery
Install the aerosol generator $15 \mathrm{~cm}$ proximal to the Y-piece
Device-related strategies
Metered dose inhaler
Heat it and shake it before actuation
Use an appropriate connector
Use a spacer
Coordinate actuation with inhalation
Nebulizer
Use an intermittent-flow nebulizer system only if the gas source is $>15 \mathrm{psi}$
If an external flow source is used, use a flow rate of $6-8 \mathrm{~L} / \mathrm{min}$
Complete the volume by adding $2.5 \mathrm{~mL}$ of saline solution

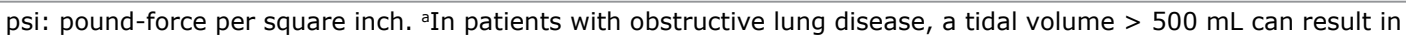
auto-PEEP (dynamic hyperinflation). In such cases, respiratory mechanics should be monitored, tidal volume being controlled in order to avoid barotrauma.

Chart 2. Doses and duration of action of the inhaled bronchodilators most commonly administered to patients on mechanical ventilation.

\begin{tabular}{|c|c|c|c|c|c|}
\hline Drug & Formulation & Dose & $\begin{array}{c}\text { Onset of } \\
\text { action, min }\end{array}$ & $\begin{array}{l}\text { Time to peak } \\
\text { effect, min }\end{array}$ & $\begin{array}{l}\text { Frequency of } \\
\text { use, number of } \\
\text { times/day }\end{array}$ \\
\hline \multicolumn{6}{|c|}{$\beta_{2}$ agonist } \\
\hline $\begin{array}{c}\text { Fenoterol } \\
\text { hydrobromide }\end{array}$ & $\begin{array}{l}\text { Solution: } 5 \mathrm{mg} / \mathrm{mL} \\
\text { Aerosol: } 100 \mu \mathrm{g} / \text { jet }\end{array}$ & $\begin{array}{c}5-8 \text { drops } \\
1 \text { jet every } 5 \text { min }\end{array}$ & $5-10$ & 15 & $3-6$ \\
\hline Albuterol & Aerosol: $100 \mu \mathrm{g} / \mathrm{jet}$ & 2 jets & $5-15$ & $30-60$ & $4-6$ \\
\hline \multicolumn{6}{|c|}{ Anticholinergic agent } \\
\hline Ipratropium bromide & $\begin{array}{c}\text { Solution: } 0.25 \mathrm{mg} / \mathrm{mL} \\
\text { Aerosol: } 20 \mu \mathrm{g} / \mathrm{jet}\end{array}$ & $\begin{array}{c}20-40 \text { drops } \\
4 \text { jets }\end{array}$ & 15 & $90-120$ & 4-6 \\
\hline
\end{tabular}

inspiratory limb of the ventilator circuit acts as an aerosol reservoir during exhalation. ${ }^{(19)}$ Synchronization of actuation with the beginning of inhalation increases lung drug deposition by as much as $30 \%$ when compared with failure to synchronize actuations with inhalation. A delay of 1-1.5 s between actuation and inhalation can reduce the efficacy of drug delivery. ${ }^{(13)}$

Ventilator settings also play an important role in inhaled drug delivery. A tidal volume of at least 500 $\mathrm{mL},{ }^{(20)}$ increased inspiratory time, and low inspiratory flow (30-50 L/min) are recommended in order to optimize lung drug deposition. ${ }^{(16,18,20)}$ Attention should be paid to the adverse effects of high ( $>500 \mathrm{~mL}$ ) tidal volume in patients with obstructive lung disease, given that it can worsen dynamic hyperinflation or cause barotrauma. According to the authors of an in vitro study, drug delivery by nebulizers can vary depending on the ventilation mode (i.e., pressure-controlled ventilation or volume-controlled ventilation). ${ }^{(21)}$ However, there have been no clinical studies showing the beneficial effects of any particular ventilation mode on inhaled drug delivery. ${ }^{(6)}$
High and turbulent flows can increase particle impaction, increasing particle deposition in the proximal airways. $^{(17)}$ The density of the inhaled gas also influences drug delivery. Inhalation of a less dense gas, such as a 70/30 mixture of helium and oxygen, makes airflow less turbulent and more laminar, facilitating inhaled drug delivery. ${ }^{(22,23)}$

\section{BRONCHODILATOR RESPONSE DURING MV}

Given that it is impossible to assess $\mathrm{FEV}_{1}$ and FVC in patients on MV, treatment response is evaluated on the basis of respiratory mechanics parameters. Treatment is aimed at reducing inspiratory airway resistance. Reduced inspiratory airway resistance can be confirmed by a reduction in peak pressure or in the difference between peak and plateau pressures during an inspiratory pause. A reduction of more than $10 \%$ in the variation in resistance indicates a significant bronchodilator response. ${ }^{(6)}$ It is important to analyze pre- and post-bronchodilator flow curves, which can 
Chart 3. Factors influencing aerosol deposition in the airways during mechanical ventilation.

\begin{tabular}{|c|c|c|}
\hline Factors & Parameters & Influence on aerosol deposition \\
\hline Ventilator-related & $\begin{array}{l}\text { Ventilation mode } \\
\text { Tidal volume } \\
\text { Respiratory rate } \\
\text { Inspiratory/expiratory time ratio } \\
\text { Inspiratory flow } \\
\text { Inspiratory trigger }\end{array}$ & $\begin{array}{l}\text { In vitro studies have shown that aerosol } \\
\text { deposition varies depending on the ventilation } \\
\text { mode. } \\
\text { A longer inspiratory time translates to better } \\
\text { drug delivery. }\end{array}$ \\
\hline Circuit-related & $\begin{array}{l}\text { Endotracheal tube size } \\
\text { Inhaled gas humidity } \\
\text { Inhaled gas density }\end{array}$ & $\begin{array}{l}\text { A larger tube translates to a more turbulent } \\
\text { flow and worse drug delivery. }\end{array}$ \\
\hline Nebulizer-related & $\begin{array}{l}\text { Nebulizer type } \\
\text { Inhaled volume } \\
\text { Gas flow } \\
\text { Nebulization cycling: inspiratory vs. continuous } \\
\text { Duration of nebulization } \\
\text { Position in the ventilator circuit }\end{array}$ & $\begin{array}{l}\text { High, turbulent flows increase drug deposition } \\
\text { in the proximal airways, thus reducing drug } \\
\text { efficacy. }\end{array}$ \\
\hline $\begin{array}{l}\text { Metered dose } \\
\text { inhaler-related }\end{array}$ & $\begin{array}{l}\text { Type of spacer and connector } \\
\text { Position of the spacer } \\
\text { Coordination of actuation with inhalation } \\
\text { Type of metered dose inhaler }\end{array}$ & $\begin{array}{l}\text { Failure to coordinate actuation with } \\
\text { inhalation results in lower lung drug } \\
\text { deposition. }\end{array}$ \\
\hline Drug-related & $\begin{array}{l}\text { Dose } \\
\text { Formulation } \\
\text { Aerosol particle size } \\
\text { Duration of action }\end{array}$ & $\begin{array}{l}\text { During mechanical ventilation, higher doses } \\
\text { of inhaled bronchodilators are required. }\end{array}$ \\
\hline Patient-related & $\begin{array}{l}\text { Severity of airway obstruction } \\
\text { Mechanism of airway obstruction } \\
\text { Dynamic hyperinflation } \\
\text { Patient-ventilator synchrony }\end{array}$ & $\begin{array}{l}\text { Severe airway obstruction and auto-PEEP } \\
\text { reduce deposition of bronchodilators in the } \\
\text { more distal airways, thus reducing drug } \\
\text { efficacy. }\end{array}$ \\
\hline
\end{tabular}

Adapted from Dhand. ${ }^{(15)}$

show a reduction in intrinsic PEEP, i.e., a reduction in auto-PEEP. ${ }^{(6)}$

\section{BRONCHODILATOR THERAPY DURING NIMV}

Given the scientific evidence for the use of NIMV in patients with COPD or asthma, it is necessary to study bronchodilator administration during NIMV. Currently, in daily practice, for bronchodilator administration in patients on NIMV, the mask is removed and the drug is delivered as usual (i.e., by a nebulizer or MDI), or the device is connected to the mask or the ventilator circuit. There is currently no commercially available system designed specifically for inhalation therapy during NIMV. ${ }^{(24)}$

As is the case with invasive MV, the effect of the inhaled drug during NIMV depends on the pharmacological properties of the drug and on lung drug deposition. For better drug delivery, aerosol particles must be small enough to penetrate through the upper airways but large enough to avoid being eliminated by the expiratory flow. Devices that produce aerosols with mass of less than $2 \mu \mathrm{m}$ are more efficient for pulmonary deposition during NIMV. ${ }^{(17)}$

In NIMV-dependent patients, an MDI with a spacer was found to be four to six times more efficient for bronchodilator administration than an MDI without a spacer. ${ }^{(17)}$ Nava et al. ${ }^{(25)}$ evaluated MDI-delivered albuterol in clinically stable COPD patients who were on NIMV and in those who were not. The authors found a significant increase in $\mathrm{FEV}_{1}$ after albuterol administration, regardless of the method used. ${ }^{(25)}$

Aerosol deposition in the mask and nasal cavity significantly reduces lung drug deposition, (17,26-28) possibly reducing drug efficacy. However, a mask is required for ventilatory support in some patients with bronchospasm, in whom it can avoid intubation. ${ }^{(29-32)}$ For increased efficacy, the mask must be well secured. Leaks can significantly reduce drug delivery. ${ }^{(33)}$

Ventilators specifically designed for NIMV have a single-limb circuit, and exhalation valve position can influence the efficiency of aerosol delivery; this does not occur when an MDI is used. (17) Branconnier \& Hess $^{(34)}$ used an experimental model in which the leak port was incorporated either into the circuit or into the mask in order to determine whether albuterol delivered during NIMV was affected by the use of a nebulizer or an MDI. The authors found that, with the nebulizer, significantly more albuterol was delivered when the leak port was in the circuit than when it was in the mask. ${ }^{(34)}$ Calvert et al. ${ }^{(35)}$ reported that albuterol delivery was more efficient when the nebulizer was placed between 


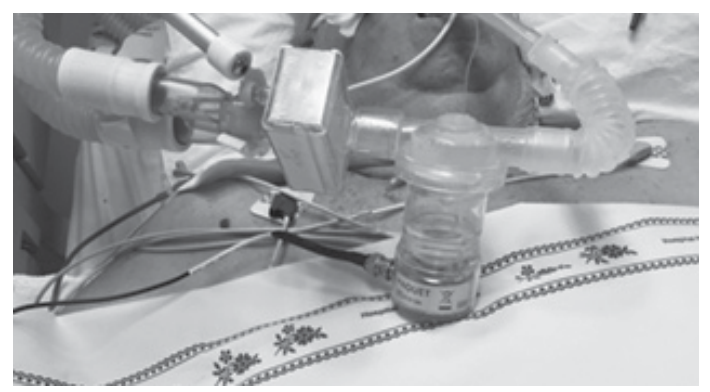

Figure 1. The aerosol generator should be placed at a distance of $20-30 \mathrm{~cm}$ from the endotracheal tube, between the tube and the Y-piece of the ventilator circuit.

the exhalation port and the ventilator for NIMV than when the nebulizer was placed between the exhalation port and the mask. In contrast, Abdelrahim et al. ${ }^{(36)}$ observed higher aerosol deposition when the nebulizer was placed between the exhalation port and the mask. The divergent results show that this is a controversial issue and indicate the need for further studies.

The position of the nebulizer in relation to the mask also plays an important role in aerosol deposition, front-loaded nebulizers being more efficient than bottom-loaded nebulizers in delivering drug to the patient. ${ }^{(37)}$ An in vitro study investigating the effect of ventilator settings and nebulizer position on albuterol delivery during NIMV showed that albuterol delivery varied significantly depending on nebulizer position in the ventilator circuit, inspiratory/expiratory pressure levels, and respiratory rate. Albuterol delivery was greatest (with as much as $25 \%$ of the nominal dose being delivered) when the nebulizer was placed between the mask and the circuit, when inspiratory pressure was highest $\left(20 \mathrm{cmH}_{2} \mathrm{O}\right)$, and when expiratory pressure was lowest $\left(5 \mathrm{CmH}_{2} \mathrm{O}\right) \cdot{ }^{(38)}$

The extent of lung disease and the ability of patients to tolerate the mask also play a decisive role in the success of treatment with NIMV and inhalation therapy. Patient-ventilator synchrony improves lung drug deposition. A delay of 1-1.5 $\mathrm{s}$ between device actuation and the beginning of inhalation can significantly reduce the efficiency of drug delivery. ${ }^{(13,17)}$

\section{FINAL CONSIDERATIONS}

Many patients with COPD require ventilatory support via invasive MV or NIMV. Inhaled drug delivery is complex in this context. Multiple factors influence the efficacy of inhaled bronchodilators administered during MV. For improved drug efficacy, the appropriate dose and formulation should be prescribed. Measures that can improve the efficacy of bronchodilators include the use of a spacer, patient-ventilator synchrony, an appropriate interval between doses, and adjustment of the ventilator settings during administration.

Despite the recommendations for inhaled drug delivery, few such interventions are implemented in daily clinical practice. Knowledge of the factors influencing lung drug deposition is fundamental to optimizing the treatment of these patients.

\section{REFERENCES}

1. Jezler S, Holanda MA, José A, Franca S. Mechanical ventilation in decompensated chronic obstructive pulmonary disease (COPD) [Article in Portuguese]. J Bras Pneumol. 2007;33 Suppl 2S:S111-8. http://dx.doi.org/10.1590/S1806-37132007000800006

2. Ehrmann S, Roche-Campo F, Sferrazza Papa GF, Isabey D, Brochard L, Apiou-Sbirlea G, et al. Aerosol therapy during mechanical ventilation: an international survey. Intensive Care Med. 2013;39(6):1048-56. http://dx.doi.org/10.1007/s00134-013-2872-5

3. Maclntyre NR, Silver RM, Miller CW, Schuler F, Coleman RE. Aerosol delivery in intubated, mechanically ventilated patients. Crit Care Med. 1985;13(2):81-4. http://dx.doi.org/10.1097/00003246-19850200000005

4. Kallet $\mathrm{RH}$. Adjunct therapies during mechanical ventilation: airway clearance techniques, therapeutic aerosols, and gases. Respir Care. 2013;58(6):1053-73. http://dx.doi.org/10.4187/respcare.02217

5. Marik P, Hogan J, Krikorian J. A comparison of bronchodilator therapy delivered by nebulization and metered-dose inhaler in mechanically ventilated patients. Chest. 1999;115(6):1653-7. http://dx.doi. org/10.1378/chest.115.6.1653

6. Dhand R. Bronchodilator Therapy. In: Tobin MJ, editor. Principles and Practice of Mechanical Ventilation. 3rd ed. Chicago: McGraw Hill Medical; 2013.1419-46.

7. Duarte AG. Inhaled bronchodilator administration during mechanical ventilation. Respir Care. 2004;49(6):623-34.

8. Menezes AM, Macedo SE, Noal RB, Fiterman J, Cukier A, Chatkin JM, et al. Pharmacological treatment of COPD. J Bras Pneumol. 2011;37(4):527-43. http://dx.doi.org/10.1590/S180637132011000400016

9. Sears MR, Lötvall J. Past, present and future--beta2-adrenoceptor agonists in asthma management. Respir Med. 2005;99(2):152-70. http://dx.doi.org/10.1016/..rmed.2004.07.003

10. Travers $A H$, Rowe BH, Barker $S$, Jones A, Camargo CA Jr. The

effectiveness of IV beta-agonists in treating patients with acute asthma in the emergency department: a meta-analysis. Chest. 2002;122(4):1200-7. http://dx.doi.org/10.1378/chest.122.4.1200

11. Camargo CA Jr, Spooner $\mathrm{CH}$, Rowe $\mathrm{BH}$. Continuous versus intermittent beta-agonists in the treatment of acute asthma. Cochrane Database Syst Rev. 2003;(4)CD001115.

12. Dhand R, Tobin MJ. Inhaled bronchodilator therapy in mechanically ventilated patients. Am J Respir Crit Care Med. 1997;156(1):3-10 http://dx.doi.org/10.1164/ajrccm.156.1.9610025

13. Diot P, Morra L, Smaldone GC. Albuterol delivery in a model of mechanical ventilation. Comparison of metered-dose inhaler and nebulizer efficiency. Am J Respir Crit Care Med. 1995; 152/4 Pt 1):1391-4. http://dx.doi.org/10.1164/ajrccm.152.4.7551401

14. Bishop MJ, Larson RP, Buschman DL. Metered dose inhaler aeroso characteristics are affected by the endotracheal tube actuator/ adapter used. Anesthesiology. 1990;73(6):1263-5. http://dx.doi. org/10.1097/00000542-199012000-00027

15. Dhand R. Basics techniques for aerosol delivery during mechanical ventilation. Respir Care. 2004;49(6):611-22.

16. Dhand R, Guntur VP. How best to deliver aerosol medications to mechanically ventilated patients. Clin Chest Med. 2008;29(2):277-96. http://dx.doi.org/10.1016/j.ccm.2008.02.003

17. Dhand R. Aerosol therapy in patients receiving noninvasive positive pressure ventilation. J Aerosol Med Pulm Drug Deliv. 2012;25(2):6378. http://dx.doi.org/10.1089/jamp.2011.0929

18. Guerin C, Fassier T, Bayle F, Lemasson S, Richard JC. Inhaled bronchodilator administration during mechanical ventilation: how to optimize it, and for which clinical benefit? J Aerosol Med Pulm Drug Deliv. 2008;21(1):85-96. http://dx.doi.org/10.1089/jamp.2007.0630

19. Ari A, Areabi H, Fink JB. Evaluation of aerosol generator devices at 3 locations in humidified and non-humidified circuits during adult mechanical ventilation. Respir Care. 2010;55(7):837-44. 
20. Fink JB, Dhand R, Duarte AG, Jenne JW, Tobin MJ. Aerosol delivery from a metered-dose inhaler during mechanical ventilation. An in vitro model. Am J Respir Crit Care Med. 1996;154(2 Pt 1):382-7. http://dx.doi.org/10.1164/ajrccm.154.2.8756810

21. Hess DR, Dillman C, Kacmarek RM. In vitro evaluation of aerosol bronchodilator delivery during mechanical ventilation: pressurecontrol vs. volume control ventilation. Intensive Care Med. 2003;29(7):1145-50. http://dx.doi.org/10.1007/s00134-003-1792-1

22. Goode ML, Fink JB, Dhand R, Tobin MJ. Improvement in aeroso delivery with helium-oxygen mixtures during mechanical ventilation. Am J Respir Crit Care Med. 2001;163(1):109-14. http://dx.doi. org/10.1164/ajrccm.163.1.2003025

23. Hess DR, Acosta FL, Ritz RH, Kacmarek RM, Camargo CA Jr. The effect of heliox on nebulizer function using a beta-agonist bronchodilator. Chest. 1999;115(1):184-9. http://dx.doi.org/10.1378/ chest.115.1.184

24. Hess DR. The mask for noninvasive ventilation: principles of design and effects on aerosol delivery. J Aerosol Med. 2007;20 Suppl 1:S8598; discussion S98-9.

25. Nava S, Karakurt S, Rampulla C, Braschi A, Fanfulla F. Salbutamo delivery during non-invasive mechanical ventilation in patients with chronic obstructive pulmonary disease: a randomized, controlled study. Intensive Care Med. 2001;27(10):1627-35. http://dx.doi org/10.1007/s001340101062

26. Chua HL, Collis GG, Newbury AM, Chan K, Bower GD, Sly PD, et al. The influence of age on aerosol deposition in children with cystic fibrosis. Eur Respir J. 1994;7(12):2185-91. http://dx.doi.org/10.1183/ 09031936.94.07122185

27. Everard ML, Hardy JG, Milner AD. Comparison of nebulized aeroso deposition in the lungs of healthy adults following oral and nasal inhalation. Thorax. 1993;48(10):1045-6. http://dx.doi.org/10.1136/ thx.48.10.1045

28. Kishida M, Suzuki I, Kabayama H, Koshibu T, Izawa M, Takeshita Y, et al. Mouthpiece versus facemask for delivery of nebulized salbutamo in exacerbated childhood asthma. J Asthma. 2002;39(4):337-9. http:// dx.doi.org/10.1081/JAS-120002291

29. Quon BS, Gan WQ, Sin DD. Contemporary management of acute exacerbations of COPD: a systematic review and metaanalysis
Chest. 2008;133(3):756-66. http://dx.doi.org/10.1378/chest.07-1207

30. Lightowler JV, Wedzicha JA, Elliott MW, Ram FS. Non-invasive positive pressure ventilation to treat respiratory failure resulting from exacerbations of chronic obstructive pulmonary disease: Cochrane systematic review and meta-analysis. BMJ. 2003;326(7382):185 http://dx.doi.org/10.1136/bmj.326.7382.185

31. Ram FS, Picot J, Lightowler JV, Wedzicha JA. Non-invasive positive pressure ventilation for treatment of respiratory failure due to exacerbations of chronic obstructive pulmonary disease. Cochrane Database Syst Rev. 2004;(3):CD004104. http://dx.doi org/10.1002/14651858.cd004104.pub3

32. Keenan SP, Sinuff T, Cook DJ, Hill NS. Which patients with acute exacerbation of chronic obstructive pulmonary disease benefit from noninvasive positive-pressure ventilation? A systematic review of the literature. Ann Intern Med. 2003;138(11):861-70. http://dx.doi. org/10.7326/0003-4819-138-11-200306030-00007

33. Erzinger S, Schueepp KG, Brooks-Wildhaber J, Devadason SG Wildhaber JH. Facemasks and aerosol delivery in vivo. J Aerosol Med. 2007;20 Suppl 1:S78-83; discussion S83-4.

34. Branconnier MP, Hess DH. Albuterol delivery during noninvasive ventilation. Respir Care. 2005;50(12):1649-53.

35. Calvert LD, Jackson JM, White JA, Barry PW, Kinnear WJ $\mathrm{O}^{\prime}$ Callaghan C. Enhanced delivery of nebulised salbutamol during non-invasive ventilation. J Pharm Pharmacol. 2006;58(11):1553-7. http://dx.doi.org/10.1211/jpp.58.11.0017

36. Abdelrahim ME, Plant $P$, Chrystyn $H$. In-vitro characterisation of the nebulised dose during non-invasive ventilation. J Pharm Pharmacol. 2010;62(8):966-72. http://dx.doi.org/10.1111/j.20427158.2010.01134.x

37. Smaldone GC, Sangwan S, Shah A. Facemask design, facia deposition, and delivered dose of nebulized aerosols. J Aerosol Med. 2007;20 Suppl 1:S66-75; discussion S75-7.

38. Chatmongkolchart S, Schettino GP, Dillman C, Kacmarek RM, Hess DR. In vitro evaluation of aerosol bronchodilator delivery during noninvasive positive pressure ventilation: effect of ventilator settings and nebulizer position. Crit Care Med. 2002;30(11):2515-9. http:// dx.doi.org/10.1097/00003246-200211000-00018 